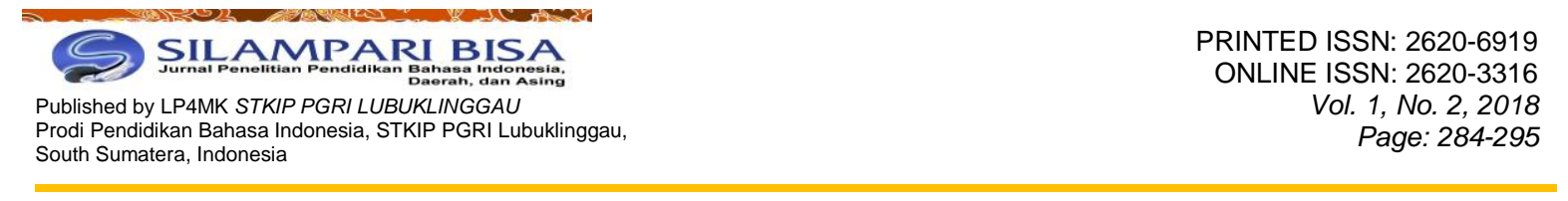

\title{
SIKAP PEMERTAHANAN BAHASA JAWA PADA MASYARAKAT DESA G2 DWIJAYA KECAMATAN TUGUMULYO KABUPATEN MUSI RAWAS
}

\author{
Syaiful Abid ${ }^{1}$, Nur Nisai Muslihah ${ }^{2}$, \& Lesy Puspitasari ${ }^{3}$ \\ 1,2,3STKIP PGRI Lubuklinggau \\ Jln. Mayor Toha Kelurahan Air Kuti, Kota Lubuklinggau, Kode Pos 31625 , Indonesia \\ Email: syaifulabid@stkippgri-lubuklinggau.ac.id,nurnisai@stkippgri-lubuklinggau.ac.id, \\ lesypuspitasari26@yahoo.com
}

\begin{abstract}
Abstrak
Tujuan penelitian ini untuk mendeskripsikan sikap pemertahanan bahasa Jawa pada masyarakat Desa G2 Dwijaya Kecamatan Tugumulyo Kabupaten Musi Rawas pada ranah remaja dan dewasa. Metode penelitian menggunakan metode deskriptif kualitatif. Subjek penelitian ini adalah anakanak, remaja, dan dewasa yang berjumlah 180 orang. Teknik pengumpulan data dilakukan dengan menggunakan teknik angket. Data yang sudah terkumpul kemudian dianalisis sesuai dengan langkah-langkah analisis data, dimulai dengan penskoran, interpretasi, dan membuat kesimpulan. Dari hasil analisis data diketahui bahwa sikap pemertahanan bahasa Jawa dari golongan remaja dengan nilai rata-rata yaitu 89,38 dengan kategori sangat baik, dan untuk remaja dengan nilai ratarata yaitu 88,97 dengan kategori sangat baik. Dengan demikian, sikap pemertahanan bahasa Jawa pada masyarakat Desa G2 Dwijaya Kecamatan Tugumulyo Kabupaten Musi Rawas mencapai nilai rata-rata yaitu 89,18 dengan kategori sikap pemertahanan bahasa Jawa yang sangat baik.
\end{abstract}

Kata kunci: sikap pemertahanan, bahasa Jawa, masyarakat

\section{JAVA LANGUAGE RESISTANCE ATTITUDE IN THE COMMUNITY OF G2 VILLAGE DWIJAYA TUGUMULYO SUBDISTRICT MUSI RAWAS DISTRICT}

\begin{abstract}
The objective of this research was to describe the attitude of Javanese language retention in the community of G2 Dwijaya Village, Tugumulyo Subdistrict, Musi Rawas District in the realm of adolescents and adults. The research method uses a qualitative descriptive method. The subjects of this research were 180 children, adolescents, and adults. Data collection techniques were carried out using questionnaire techniques. The collected data is then analyzed according to the steps of data analysis, starting with scoring, interpretation, and making conclusions. From the results of data analysis, it is known that the attitude of Javanese language retention from adolescents with an average value is 89.38 with a very good category, and for adolescents with an average value of 88.97 with very good categories. Thus, the attitude of Javanese language retention to the people of G2 Dwijaya Village, Tugumulyo District, Musi Rawas Regency reached an average value of 89.18 with a very good Javanese language defense attitude category.
\end{abstract}

Keywords: defence attitude, Javanese language, society 


\section{A. Pendahuluan}

Masyarakat Indonesia merupakan masyarakat yang tingkat heterogenitasnya luar biasa banyak. Masyarakat heterogen adalah masyarakat yang beragam atau bervariasi. Oleh karena itu, masyarakat yang demikian ini mempunyai bahasa, suku, dan BUDAYA yang berbeda-beda. Perbedaanperbedaan suku, bangsa, agama, adat istiadat, dan kedaerahan dalam struktur horizontal sering disebut juga sebagai ciri masyarakat majemuk (Nasikun dalam Handoko, 2015:7). Perbedaan-perbedaan secara horizontal, dimaknai sebagai perbedaan yang tidak diukur berdasarkan kualitas dari unsur-unsur yang membuat keragaman tersebut. Dengan keberagaman bahasa dan penggunaan bahasa pada masyarakat Indonesia, secara otomatis menjadi masyarakat yang multilingual.

Masyarakat multilingual adalah kelompok masyarakat yang memiliki kemampuan menggunakan lebih dari dua bahasa, seperti bahasa daerah, Indonesia, dan asing. Bahasa merupakan salah satu media komunikasi yang digunakan seseorang dalam berinteraksi baik individu maupun kelompok. Bahasa memegang peranan penting dalam kehidupan manusia, baik dalam bidang pendidikan maupun bidang lainnya. Berkaitan dengan hal ini, bahasa adalah sistem lambang bunyi yang arbitrer yang dipergunakan oleh para anggota kelompok sosial untuk bekerja sama, berkomunikasi, dan mengidentifikasi diri Achmad \& Abdullah (2013:3) mengemukakan bahwa bahasa merupakan alat verbal yang digunakan untuk berkomunikasi. Melalui bahasa, seseorang telah melakukan proses komunikasi secara verbal.

Bangsa Indonesia memiliki bahasa Indonesia sebagai bahasa persatuan. Bangsa Indonesia juga memiliki bahasa daerah yang sangat banyak jumlahnya. Hampir setiap daerah memiliki bahasa daerah yang berfungsi sebagai alat komunikasi antar anggota masyarakat dan ciri khas daerahnya tersebut. Bahasa daerah merupakan bahasa yang dipakai dalam suatu lingkungan masyarakat yang terbatas yang menjadi bagian dari lingkungan yang lebih kecil. Lain halnya dengan pendapat Samuel (2005:77) bahwa bahasa daerah merupakan salah satu unsur dan sekaligus alat pembentuk kepribadian budaya bangsa. Bahasa daerah berfungsi untuk melakukan interaksi sesama manusia. Bahasa daerah juga 
disebut sebagai salah satu kekayaan dan warisan budaya bangsa yang tiada ternilai yang harus dilestarikan dan dipertahankan (Wahyuni, 2010: 77).

Pada tingkat daerah, bahasa-bahasa daerah menjalankan fungsi yang lebih beragam yaitu: (1) dari segi kebahasaan, bahasa-bahasa ini hanya diakui karena nilai manfaatnya sebagai bahasa penghubung intradaerah atau lebih tepatnya alat penghubung di dalam keluarga dan masyarakat daerah; (2) dari segi bahasa, bahasa-bahasa daerah ikut menyumbang dalam membentuk identitas budaya daerah, sebagaimana halnya hukum, adat, rumah adat, seni pertunjukan dan lain sebagainya, sebagai lambang kebanggaan daerah, lambang identitas daerah, dan sebagai alat pengembangan serta pendukung kebudayaan daerah dan memelihara warisan kebudayaan daerah (Samuel, 2005:77).

Fungsi bahasa daerah adalah sebagai alat komunikasi maupun alat untuk mengenal identitas daerah-daerah, di mana bahasa itu digunakan. Seperti pada masyarakat Desa G2 Dwijaya (Patok 40) yang terletak di Kecamatan Tugumulyo Kabupaten Musi Rawas, Provinsi Sumatera Selatan. Desa G2 Dwijaya memiliki penutur yang sebagian menggunakan bahasa daerah yaitu bahasa Jawa, walaupun berada di daerah Sumatera. Hal ini dikarenakan Desa G2 Dwijaya merupakan salah satu wilayah transmigrasi yang berasal dai penduduk Pulau Jawa. Peran bahasa Jawa di G2 Dwijaya digunakan sebagai alat komunikasi di dalam kehidupan sehari-hari. Saat ini penduduk desa G2 Dwijaya tersebut masih mampu mempertahankan bahasa daerahnya tersebut.

Pemertahanan bahasa adalah suatu gejala dimana seseorang tetap berusaha agar bahasanya dapat tetap dipakai dan dihargai banyak orang sebagai suatu identitas dalam konteks sosial, baik di lingkungan pendidikan maupun lingkungan masyarakat. Fishman (dalam Alika dkk., 2017:194) mengatakan bahwa pemertahanan bahasa (language maintenance) bergantung pada ideologi nasional dalam masyarakat atau bergantung paling sedikit pada ideologi yang dimiliki masyarakat yang mempertahankan konteks sosial mereka untuk melawan perubahan yang datang.

Di sisi lain pergeseran bahasa, menyangkut masalah penggunaan bahasa oleh seorang penutur atau sekelompok penutur yang bisa terjadi sebagai akibat 
perpindahan dari satu masyarakat tutur ke masyarakat tutur lain. Pemertahanan dan pergeseran bahasa adalah dua gejala kebahasaan yang saling terkait. Bahasa dikatakan mengalami pergeseran ketika suatu masyarakat mulai meninggalkan bahasa tradisionalnya (bahasa daerah atau bahasa ibu). Begitupun dengan bahasa Jawa, masyarakat Jawa saat ini mulai mengacuhkan bahasanya sendiri karena gempuran ilmu pengetahuan dan teknologi (IPTEK) di berbagai ranah, khususnya dalam ranah pendidikan.

Bahasa Jawa merupakan contoh bahasa daerah di Indonesia yang masih digunakan sebagai sarana komunikasi masyarakat yang bukan hanya di pulau Jawa, tetapi di hampir setiap daerah karena masyarakat Jawa menjadi masyarakat yang terbesar mengikuti program transmigrasi. Meskipun demikian masyarakat Jawa mulai merasa cemas akan eksistensi bahasa Jawa. Pada era globalisasi, pemakaian bahasa Jawa tidak lagi bersifat monolingual, tetapi cenderung multilingual (Kholidah, 2015:105). Bahasa Jawa memiliki fungsi tersendiri sebagai identitas dan jati diri sebagai orang jawa agar tidak kehilangan ciri khasnya. Bahasa Jawa hidup berdampingan dengan bahasa lain yaitu bahasa Indonesia dan bahasa lainnya. Pergeseran bahasa Jawa dalam masyarakat menjadi ancaman bagi keberadaan bahasanya sebagai identitas dan jati diri. Pemertahanan bahasa Jawa harus dilakukan oleh masyarakatnya sendiri agar identitas dan jati diri dari masyarakat tetap terjaga.

Bahasa Jawa merupakan salah satu bahasa daerah di Indonesia yang masih digunakan sebagai sarana komunikasi masyarakatnya. Dalam bahasa Jawa dikenal adanya undak usuk bahasa atau sering disebut tingkatan bahasa (Chaer, 2010:40). Ada tiga jenis bahasa Jawa diantaranya Jawa Ngoko, Jawa Madya, dan Jawa Krama. Bahasa Jawa Ngoko digunakan oleh seseorang yang seusia atau sudah dikenal dekat. Sedangkan bahasa Jawa Krama dan Jawa Madya adalah bahasa Jawa halus yang biasanya digunakan ketika berbicara dengan orang yang lebih tua. Contohnya, bahasa Jawa Ngoko, "Koe arep menyang ngendi Pak?" yang artinya "Kamu mau kemana Pak?". Bahasa Jawa Krama dan Jawa Madya, misalnya "Sampean ajeng teng pundi Pak?" yang artinya "Kamu mau ke mana Pak?. Itulah perbedaan antara bahasa Jawa Ngoko, bahasa Jawa Madya, dan bahasa Jawa Krama. 
Beberapa hasil penelitian relevan pernah dilakukan oleh Yolla (2010) dan Kholidah (2015). Penelitian Yolla (2010) dengan judul Pemertahanan Bahasa Cina Chek pada Masyarakat Etnis Tionghoa di Kampung Bintang Kota Pangkalpinang. Hasil penelitian ini menjelaskan tentang bagaimana situasi pemertahanan bahasa Cina Khek pada ranah keluarga, keariban, tetangga, pendidikan, agama, transaksi, dan pemerintahan pada masyarakat Etnis Tionghoa di Kampung Bintang Kota Pangkalpinang. Persamaan penelitian ini adalah sama-sama membahas pemertahanan bahasa, perbedaannya dari segi bahasa yang akan diteliti, dan objek penelitian.

Kemudian penelitian yang dilakukan oleh Kholidah (2015:105) menjelaskan bahwa pola pemertahanan bahasa pada interaksi siswa dengan guru di MTS AlHikmah Pasir Demak, sebanyak tiga pola, yaitu: 1) pola hubungan siswa dengan guru, 2) pola hubungan guru dengan siswa, dan (3) pola hubungan siswa dengan siswa, yang ditandai dengan penggunaan bahasa Jawa. Kemudian, faktor yang sangat memengaruhi adanya pemertahanan bahasa Jawa dalam interaksi siswa dengan guru berupa faktor geografis, situasional, dan kesinambungan pengalihan (transmisi) bahasa Jawa dari generasi ke generasi berikutnya. Data dari penelitian ini berupa data dalam kelas, berbeda dengan data dalam penelitian ini berupa komunikasi dalam masyarakat desa.

Berdasarkan beberapa penelitian relevan di atas menunjukkan bahwa belum pernah diteliti sikap pemertahanan bahasa Jawa pada masyarakat Desa G2 Dwijaya Kecamatan Tugumulyo Kabupaten Musi Rawas. Untuk itu penelitian ini ingin menjawab rumusan masalah "Bagaimanakah sikap pemertahanan bahasa Jawa pada masyarakat Desa G2 Dwijaya Kecamatan Tugumulyo Kabupaten Musi Rawas? Dengan tujuan memberikan gambaran yang utuh tentang sikap pemertahanan bahasa Jawa pada masyarakat Desa G2 Dwijaya Kecamatan Tugumulyo Kabupaten Musi Rawas. 


\section{B. Metode Penelitian}

Metode yang digunakan dalam penelitian ini menggunakan metode deskriptif kualitatif yang bertujuan untuk mendapatkan pemaparan yang bersifat aktual dan alami mengenai sikap pemertahanan bahasa Jawa di masyarakat Desa G2 Dwijaya Kecamatan Tugumulyo Kabupaten Musi Rawas. Penelitian ini dilaksanakan di Desa G2 Dwijaya Kecamatan Tugumulyo Kabupaten Musi Rawas, dan waktu penelitian dimulai pada tanggal 10 Agustus sampai 20 Agustus 2018. Penelitian kualitatif ini bertujuan untuk mendeskripsikan sikap pemertahanan terhadap bahasa Jawa, pada lingkungan remaja dan dewasa, kemudian dianalisis dan membuat kesimpulan. Data dalam penelitian ini berupa sikap pemertahanan bahasa Jawa pada masyarakat Desa G2 Dwijaya Kecamatan Tugumulyo Kabupaten Musi Rawas.

Teknik pengumpulan data yang digunakan dalam penelitian ini adalah teknik angket (kuesioner) berupa pernyataan yang akan diisi oleh responden dengan 20 item pernyataan, yang ditujukan kepada golongan remaja dan dewasa. Pengambilan sampel menggunakan purposive sampling. Menurut Sugiyono (2013:300) purposive sampling adalah teknik pengambilan sampel sumber data dengan pertimbangan tertentu. Dalam penelitian ini subjek yang digunakan penulis yaitu masyarakat Desa G2 Dwijaya dimulai dari golongan remaja, dan dewasa. Sumber data dalam penelitian ini adalah masyarakat (remaja dan dewasa) Desa G2 Dwijaya Kecamatan Tugumulyo Kabupaten Musi Rawas. Untuk mengetahui gambaran sikap pemertahanan bahasa Jawa pada masyarakat Desa G2 Dwijaya, maka dilakukan pengelompokkan data yang diperoleh ke dalam lima kategori, yaitu sangat baik, baik, cukup baik, kurang baik, dan tidak baik.

\section{Hasil Penelitian dan Pembahasan}

\section{Hasil Penelitian}

Berikut hasil penelitian tentang sikap pemertahanan bahasa Jawa pada masyarakat Desa G2 Dwijaya Kecamatan Tugumulyo Kabupaten Musi Rawas pada golongan remaja dan dewasa. 
Tabel 1. Sikap Pemertahanan Bahasa Jawa Masyarakat Desa G2 Dwijaya Kecamatan Tugumulyo Kabupaten Musi Rawas pada Golongan Remaja dan Dewasa

\begin{tabular}{|ccccccc|}
\hline No. & Golongan Usia & \multicolumn{2}{l}{ Sikap Pemertahanan Bahasa Jawa } & Jumlah & Keterangan \\
\cline { 1 - 3 } 1. & Remaja & Kognisi & Afeksi & Konasi & & \\
\cline { 3 - 5 } & 91,89 & 87,25 & 88,99 & 88,97 & $\begin{array}{c}\text { Sangat } \\
\text { Baik }\end{array}$ \\
\hline 2. & Dewasa & 90,71 & 87,12 & 89,09 & 88,79 & $\begin{array}{c}\text { Sangat } \\
\text { Baik }\end{array}$ \\
\hline
\end{tabular}

\section{Pembahasan}

Sikap pemertahanan bahasa Jawa dari golongan remaja dengan nilai ratarata yaitu 89,38 dengan kategori sangat baik, dan untuk remaja dengan nilai ratarata yaitu 88,97 dengan kategori sangat baik. Dengan demikian, sikap pemertahanan bahasa Jawa pada masyarakat Desa G2 Dwijaya Kecamatan Tugumulyo Kabupaten Musi Rawas mencapai nilai rata-rata yaitu 89,18 dengan kategori sikap pemertahanan bahasa Jawa yang sangat baik. Hal ini menunjukkan bahwa pemertahanan bahasa Jawa yang dilakukan oleh masyarakat Desa G2 Dwijaya Kecamatan Tugumulyo Kabupaten Musi Rawas masih mampu menunjukkan eksistensinya. Pemertahanan bahasa yang dilakukan oleh masyarakat Desa G2 Dwijaya, sungguh melawan ketidakberdayaan bahasa asalnya dalam persaingan dengan bahasa mayoritas yang lebih dominan di wilayah Sumatera (Sumarsono, dalam Alika dkk., 2017:194).

Pemertahanan bahasa ini juga sangat dipengaruhi oleh masih mayoritasnya penutur bahasa Jawa di Desa G2 Dwijaya, wilayah yang penduduk terkonsentrasi dengan bahasa Jawa dalam setiap aktivitasnya, dan sikap setia dalam menggunakan bahasa Jawa. Hal ini sesuai dengan pendapat Sumarsono (dalam Yolla, 2010:14), yang menyatakan empat faktor yang dapat menyebabkan suatu bahasa dapat bertahan. Empat faktor itu, yaitu: 1) wilayah pemukiman yang terkonsentrasi; 2) adanya toleransi dari masyarakat mayoritas; 3) adanya loyalitas yang tinggi dari anggota masyarakat; dan 4) adanya kesinambungan pengalih bahasa dari generasi terdahulu ke generasi berikutnya. 
Sikap pemertahanan bahasa ini sangat kuat dari golongan remaja dan dewasa, baik dari aspek kognisi, afeksi, dan konasi. Hal ini dapat dijelaskan pada pembahasan berikut.

\section{a. Pemertahanan Bahasa Jawa pada Golongan Remaja}

1) Aspek Kognisi

Hasil penelitian aspek kognisi sikap pemertahanan bahasa Jawa untuk remaja sudah menggambarkan sikap berbahasa yang sangat baik. Dapat dilihat dari hasil analisis perhitungan angket sikap pemertahanan bahasa Jawa untuk remaja dengan jumlah 26 orang didapatkan 25 dengan kategori sangat baik, dan 1 dengan kategori baik, sehingga nilai rata-rata yang diperoleh responden untuk aspek kognisi yaitu 91,89. Dari hasil nilai rata-rata dapat diketahui bahawa indikator untuk aspek kognisi yaitu bahasa Jawa tidak diperoleh secara alamiah, bahasa Jawa mudah, dan bahasa Jawa tidak lebih rendah telah tercapai dengan sangat baik. Responden mengakui bahwa sejak anak-anak dan dari masyarakatlah mereka belajar bahasa Jawa, bahasa Jawa itu menarik, dan mudah untuk dipahami dalam berkomunikasi. Dari hasil deskripsi di atas dapat disimpulkan bahwa sikap pemertahanan bahasa Jawa untuk golongan remaja aspek kognisi mencapai rata-rata sangat baik. Pada aspek ini tidak ada responden yang berada pada kategori cukup baik, kurang baik, dan tidak baik.

2) Aspek Afeksi

Hasil penelitian sikap pemertahanan bahasa Jawa pada aspek afeksi, dengan jumlah responden yaitu sebanyak 26 orang, dari hasil perhitungan angket sikap pemertahanan bahasa untuk golongan remaja memperoleh kategori sangat baik yaitu sebanyak 22 orang, dan kategori baik sebanyak 4 orang. Dari hasil rata-rata nilai tersebut dapat kita ketahui bahwa indikator bangga menggunakan bahasa Jawa telah tercapai. Kebanggaan responden terhadap bahasa Jawa ditunjukkan oleh hasil nilai rata-rata yang diperoleh yaitu 87,25 . Dari hasil nilai rata-rata tersebut, reponden sangat mengakui bahwa mereka bangga dapat menggunakan bahasa Jawa dalam keluarga maupun masyarakat. Dari deskripsi di atas dapat disimpulkan bahwa sikap pemertahanan bahasa Jawa untuk golongan remaja pada aspek afeksi dalam kategori sangat baik. Pada aspek ini 
tidak ada remaja yang berada pada kategori cukup baik, cukup, kurang baik, dan tidak baik.

3) Aspek Konasi

Dari hasil analisis perhitungan angket sikap pemertahanan bahasa Jawa didapatkan bahwa penggunaan bahasa Jawa untuk golongan remaja termasuk dalam kategori sangat baik, terbukti sebanyak 23 responden berada pada kategori sangat baik dan 3 berada pada kategori baik. Pada aspek ini tidak ada sikap remaja yang termasuk kategori cukup baik, cukup, kurang baik, dan tidak baik. Dengan demikian, pada aspek konasi sikap berbahasa remaja terhadap penggunaan bahasa Jawa rata-rata nilai yang diperoleh yaitu 88,99 denan kriteria sangat baik. Dari hasil tersebut dapat disimpulkan bahwa anak sangat bertanggung jawab dan sangat cepat tanggap dalam mempertahankan bahasa Jawa. Perhatikan tabel di bawah ini berdasarkan hasil analisis angket untuk golongan remaja yang diperoleh sebagai berikut.

Tabel 2. Sikap Pemertahanan Bahasa Jawa Masyarakat Desa G2 Dwijaya

Kecamatan Tugumulyo Kabupaten Musi Rawas pada Golongan Remaja

\begin{tabular}{|clc|}
\hline No. & \multicolumn{1}{c|}{ Aspek } & Nilai \\
\hline 1. & Kognisi & 91,89 \\
\hline 2. & Afeksi & 87,25 \\
\hline 3. & Konasi & 88,99 \\
\hline & Rata-Rata & 89,38 \\
\hline
\end{tabular}

Dari tabel di atas dapat dideskripsikan bahwa dari aspek kognisi, afeksi, dan konasi dari golongan remaja mencapai nilai rata-rata yaitu 89,38 . Dari hasil nilai rata-rata tersebut dapat disimpulkan bahwa sikap pemertahanan bahasa Jawa untuk golongan remaja dalam kategori sangat baik.

\section{b. Pemertahanan Bahasa Jawa pada Golongan Dewasa}

1) Aspek Kognisi

Hasil penelitian sikap pemertahanan bahasa Jawa menunjukkan bahwa aspek-aspek sikap berbahasa untuk golongan dewasa sudah menggambarkan sikap berbahasa yang sangat baik. Dari hasil analisis perhitungan angket sikap 
berbahasa golongan dewasa yaitu dengan jumlah 33 responden didapatkan bahwa sikap pemertahanan bahasa Jawa sangat baik sebanyak 31, dan 2 dengan kategori baik, dengan rata-rata dari keseluruhan mencapai nilai 90,71.

Dalam hal ini sangat terlihat sekali bahwa semua responden untuk golongan dewasa memiliki kategori dalam mempertahankan bahasa Jawa sangat baik, responden sangat mengakui bahwa bahasa Jawa tidak didapat secara alamiah baik dari segi masyarakat, keluarga, sejak anak-anak dan lain sebagainya, responden juga mengakui bahwa bahasa Jawa itu mudah, dan bahasa Jawa tidak lebih rendah dari bahasa lain. Pada aspek ini tidak ada sikap pemertahanan bahasa Jawa yang berada pada kategori cukup baik, cukup, kurang baik, dan tidak baik.

2) Aspek Afeksi

Hasil penelitian sikap pemertahanan bahasa Jawa menunjukkan bahwa aspek-aspek sikap berbahasa untuk golongan dewasa sudah menggambarkan sikap berbahasa yang dimilikinya. Dari hasil analisis perhitungan angket sikap berbahasa untuk golongan dewasa dengan jumlah 33 didapatkan bahwa berbahasa sangat baik sebanyak 29 orang dan sikap berbahasa golongan dewasa baik sebanyak 4 orang, dengan rata-rata nilai yaitu 87,12 . Dapat kita lihat bahwa untuk golongan dewasa pada aspek afeksi yaitu responden mengakui bahwa mereka bangga menggunakan bahasa Jawa. Pada aspek ini tidak ada golongan dewasa yang berada pada kategori cukup, kurang baik, dan tidak baik.

3) Aspek Konasi

Dari hasil analisis perhitungan angket sikap berbahasa Jawa, didapatkan bahwa sikap berbahasa golongan dewasa terhadap pemertahanan bahasa Jawa sangat baik sebanyak 27 orang dan 6 dalam kategori baik. Pada aspek ini tidak ada sikap yang termasuk kategori cukup baik, cukup, kurang baik, dan tidak baik. Dengan demikian, pada aspek ini sikap berbahasa golongan dewasa terhadap penggunaan bahasa Jawa dengan rata-rata nilai sebesar 89,09. Dalam hal ini tidak ada responden yang memiliki sikap pemertahanan bahasa Jawa cukup baik. Hal ini membuktikan bahwa masyarakat Desa G2 Dwijaya mengakui mereka sangat bertanggung jawab dan sangat siap tanggap untuk mempertahankan 
bahasa Jawa. Perhatikan tabel di bawah ini berdasarkan hasil analisis angket aspek untuk golongan dewasa yang diperoleh, sebagai berikut.

Tabel 3. Sikap Pemertahanan Bahasa Jawa Masyarakat Desa G2 Dwijaya Kecamatan Tugumulyo Kabupaten Musi Rawas pada Golongan Dewasa

\begin{tabular}{|clc|}
\hline No. & \multicolumn{1}{c|}{ Aspek } & Nilai \\
\hline 1. & Kognisi & 90,71 \\
\hline 2. & Afeksi & 87,12 \\
\hline 3. & Konasi & 87,12 \\
\hline & Rata-Rata & 88,97 \\
\hline
\end{tabular}

Dari hasil nilai rata-rata di atas dapat disimpulkan bahwa sikap pemertahanan bahasa Jawa untuk golongan dewasa pada aspek kognisi, afeksi, dan konasi yaitu mencapai nilai rata-rata sebesar 88,97 dalam kategori sangat baik.

\section{Simpulan}

Berdasarkan hasil penelitian dan pembahasan dapat disimpulkan bahwa sikap pemertahanan bahasa Jawa pada masyarakat Desa G2 Dwijaya pada golongan remaja dan golongan dewasa sangat baik dengan nilai rata-rata sebesar 89,18. Hal ini ditunjukkan dengan sikap pemertahanan bahasa Jawa dari golongan anak remaja yaitu mencakup aspek kognisi, afeksi, dan konasi yaitu dengan rata-rata sebesar 89,38 termasuk dalam kategori sangat baik, dan untuk golongan dewasa mencakup aspek kognisi, afeksi, dan konasi didapat nilai ratarata yaitu 88,97 dalam kategori sangat baik.

Dari hasil penelitian ini diharapkan terutama bagi masyarakat Desa G2 Dwijaya, agar tetap bisa menjaga dan mempertahankan bahasa Jawa-nya sebagai bahasa lbu atau bahasa pertama, walaupun tinggal di daerah Sumatera. Kemudian, bagi pembaca, diharapkan agar hasil penelitian ini dapat dimanfaatkan sebagai bahan acuan dalam menganalisis bahasa dan penelitian ini juga diharapkan dapat memberi pengetahuan tentang sikap pemertahanan bahasa Jawa dalam masyarakat. 


\section{Daftar Pustaka}

Achmad \& Abdullah, A. (2013). Linguistik Umum. Jakarta: Erlangga.

Alika, S. D., Rokhman, F., \& Haryadi. (2017). Upaya Pemertahanan Bahasa Minangkabau Ragam Nonformal pada Komunitas Seni Sakato di Kota Yogyakarta. Lingua, 13 (2).

Chaer, A. (2010). Sosiolinguistik Perkenalan Awal. Jakarta: PT Rineka Cipta.

Handoko, E. A. T. (2015). Studi Masyarakat Indonesia. Yogyakarta: Ombak.

Kholidah, U. (2015). Pemertahanan Bahasa Jawa pada Interaksi Siswa dan Guru dalam Pembelajaran Kajian Sosiolinguistik di MTS AI-Hikmah Pasir Demak. Ranah, 4 (2).

Samuel, J. (2005). Kasus Ajaib Bahasa Indonesia Situasi Sosiolinguistik. Jakarta: Kepustakaan Populer Gramedia.

Sugiyono. (2013). Metode Penelitian Pendidikan: Pendekatan Kuantitatif, Kualitatif dan $R \& D$. Bandung: Alfabeta.

Wahyuni, S. (2010). Tarik Menarik Bahasa Jawa Dialek Banyumas dan Bahasa Sunda di Perbatasan Jawa Tengah Jawa Barat Bagian Selatan sebagai Sikap Pemertahanan Bahasa oleh Penutur. Magister Linguistik PPs UNDIP, 77.

Yolla. (2010). Pemertahanan Bahasa China Khek pada Masyarakat Etnis Tinghoa di Kampung Bintang Kota Pangkal Pinang Bangka. Inderalaya: Universitas Sriwijaya. 